\title{
Projeto Mais Médicos para o Brasil em Pernambuco: uma abordagem inicial.
}

\author{
Bárbara Pinto Andrade de SOUZA ${ }^{1}$ \\ Albuquerque Cavalcanti de PAULETTE ${ }^{2}$
}

\section{INTRODUÇÃO}

A Atenção Primária à Saúde (APS), ganhou força enquanto discurso na década de 1970. No Brasil, a APS tem seus marcos históricos associados ao movimento de Reforma Sanitária e à indução à descentralização dos serviços de saúde para o nível municipal a partir da publicação das Normas Operacionais Básicas pelo Ministério da Saúde em 1996 e da criação do Programa de Saúde da Família em 1994 (STARFIELD, 2002; CONILL, 2008).

A compreensão sobre a Atenção Primária tem variado em função do tempo e da realidade de cada sistema de saúde. Vuori (1986, apud BATISTA; FAUSTO, 2009) apresentou as seguintes formas de compreender a APS: como um conjunto de atividades, como um nível de assistência, como uma estratégia de organização do sistema de serviços e como um princípio que deve nortear todas as ações desenvolvidas em um sistema.

Barbara Starfield (2002) defende que a APS deve ser compreendida como uma abordagem que forma a base e determina o trabalho de todos os outros níveis do sistema de saúde, organizando e racionalizando o uso de todos os recursos, tanto básicos como especializados, direcionados para a promoção, manutenção e melhora da saúde.

São princípios ordenadores da APS o primeiro contato com do usuário com o sistema de saúde, a longitudinalidade, a integralidade, a coordenação, a focalização na família e a orientação comunitária (STARFIELD, 2002).

Mendes (2002) observa que, na história recente de diversos países, a concepção de Atenção Primária como pilar da reorganização dos sistemas de saúde tende a superar visões mais restritas, que a colocam como um meio de oferta de serviços focalizada em populações vulneráveis ou como apenas mais um dos níveis de atenção.

1 Especialização - Residência médica pelo Centro de Pesquisas Aggeu Magalhães - Fiocruz, Brasil(2013). Referência - Programas de Provimento do Ministério da Saúde.

2 Doutorado em Saúde Pública pela Fundação Oswaldo Cruz, Brasil(2005). Pesquisadora da Fundação Oswaldo Cruz. 
No Brasil, o Programa de Saúde da Família, mais tarde elevado ao status de Estratégia, que sofreu grande expansão a partir do fim da década de 1990, configura essa tentativa de reorientar o modelo de atenção à saúde e foi responsável por grande impacto no acesso da população a serviços de saúde, assim como sobre o mercado de trabalho em saúde e na própria formação dos profissionais (MACIEL FILHO, 2007).

O Ministério da Saúde no Brasil utiliza o termo "Atenção Básica” em substituição a "Atenção Primária”, definido-a em sua Política Nacional de Atenção Básica (PNAB) como sendo:

conjunto de ações de saúde, no âmbito individual e coletivo, que abrange a promoção e a proteção
da saúde, a prevenção de agravos, o diagnóstico, o tratamento, a reabilitação, a redução de danos
e a manutenção da saúde com o objetivo de desenvolver uma atenção integral que impacte na
situação de saúde e autonomia das pessoas e nos determinantes e condicionantes de saúde das
coletividades (BRASIL, 2011).

A PNAB define que a Atenção Básica deve coordenadora de todas as Redes de Atenção à Saúde e obedecer aos princípios de universalidade, acessibilidade, vínculo, continuidade do cuidado, integralidade da atenção, responsabilização, humanização, equidade e participação social (BRASIL, 2011), em consonância com o defendido por Starfield (2002).

Um dos grandes entraves para o pleno desenvolvimento das ações da APS, apontada pelos governos de diversos países, é a dificuldade em manter a força de trabalho necessária ao desenvolvimento de suas atividades. E essa carência torna-se mais enfática quando se trata de profissionais médicos (CAMPOS, 2009). Ainda, por ser um nível de atenção de alta complexidade e baixa densidade tecnológica, a força de trabalho humana torna-se mais imprescindível, tornando a escassez destes profissionais ainda mais expressiva.

O problema da escassez de recursos humanos em saúde é complexo e, de acordo com Maciel Filho (2007), é constantemente influenciado pelas modalidades do sistema de saúde, pelas práticas assistenciais, pelo mercado de trabalho, pela legislação e regulação, pelos mecanismos de contratação, pelas práticas educativas e instituições formadoras pelas corporações profissionais e pelos movimentos sociais.

Estudos abordando o tema recursos humanos em saúde, incluindo médicos, tem sido estimulados pela Organização Panamericana da Saúde (OPAS) desde a década de 1950. Inicialmente, estes estudos enfocaram o aspecto da formação médica. No Brasil, o debate ganhou força nas décadas de 1970 e 1980, ampliando o olhar para as questões políticas, econômicas, sociais e estruturais da questão.

Porém, apesar do conhecimento acumulado na área, as tentativas de reordenamento empreendidas até então, tanto na formação quanto na gestão do trabalho, não haviam sido efetivos no enfrentamento do problema (CAMPOS et al., 2001; DAL POZ, 1996; PAIM, 1994; 
PIERANTONI, 2000 apud MACIEL FILHO, 2007).

Pode-se arriscar dizer que, de todas as iniciativas de políticas e programas, muitas delas estudadas por Maciel Filho (2007), como o Projeto Rondon, o Programa de Interiorização das Ações de Saúde e Saneamento (PIASS) e o Programa de Interiorização do SUS (PISUS) e o Programa de Interiorização do Trabalho em Saúde (PITS), o Programa Mais Médicos seja, talvez, a de maior abrangência e mais potencialmente geradora de impactos para o setor criados pelos governos brasileiros para enfrentar o problema do provimento de profissionais de saúde.

Este estudo tem por finalidade descrever a situação do Projeto Mais Médicos para o Brasil, um dos eixos do Programa Mais Médicos, implantado neste país pelo Ministério da Saúde no ano de 2013, na Atenção Primária à Saúde do estado de Pernambuco. Busca-se chegar a este objetivo através da apresentação da distribuição dos profissionais participantes no programa, bem como da investigação do possível incremento na cobertura da Estratégia de Saúde da Família.

\section{DESENVOLVIMENTO}

O setor saúde tem papel de destaque no combate às desigualdades sociais agravadas pelo processo de globalização e, no cenário atual, em que a complexidade dos problemas de saúde exige, cada vez mais, o trabalho multiprofissional e em organizações capazes de responder às mais variadas necessidades em diversos contextos sociais, a gestão de recursos humanos torna-se um verdadeiro desafio a ser superado para a obtenção de um sistema de saúde eficaz (PIERANTONI, 2007).

A Constituição Federal de 1988 define que a saúde é um direito universal que deve ser garantido pelo Estado e atribui ao Sistema Único de Saúde (SUS) a competência de ordenar e formar recursos humanos na área da saúde. Porém, chama a atenção o paradoxo existente entre o grande peso dos gastos com pessoal nos custos do sistema de saúde e a escassez de políticas para o provimento de recursos humanos para o SUS.

O SUS, desde a sua criação, convive com as desigualdades sociais, regionais e institucionais, que têm dificultado a gestão dos recursos humanos do setor, ao passo que sofre as influências da lógica econômica de produção de bens e serviços de saúde, tornando difícil ignorar o caráter de insumo que os recursos humanos têm no mercado em saúde (MACIEL FILHO, 2007).

O conceito de recursos humanos, segundo Pierantoni (2004, p. 54), vem sofrendo uma evolução, sendo (re)significado a partir de sua definição clássica, oriunda da ciência da administração, estando subordinada a à ótica de quem exerce alguma função de gerência ou de planejamento [...]. Absorve o conceito de força de trabalho da economia política com o uso descritivo e analítico dos fenômenos do mercado de trabalho - emprego/desemprego, produção, renda, assalariamento, e configura-se na gestão do trabalho, o trabalhador como "ser social" e a sociedade.

Sendo assim, é imprescindível refletir sobre o trabalho, considerado por Karl Marx (1983) como 
a essência humana. O trabalho é o elemento que diferencia o homem dos outros animais, condição necessária aos seres humanos em qualquer tempo históricoe que varia em função dos diferentes modos de produção. Através do trabalho, agindo sobre a natureza, o homem modifica a sua própria natureza.

Mendes (2010) entende o trabalho como uma atividade humana realizada por um grupo de pessoas que a ela se dedica e, assim, reproduz uma existência humana, é determinado por uma necessidade ou carência, é o meio de subsistência para a satisfação das necessidades materiais e não materiais, e também possibilita a livre criação.

O trabalho expõe a relação homem e/ou mundo em um processo de mútua produção, não devendo ser concebido como uma mera atividade e sim uma práxis geradora de relações que ajudam na construção do homem e suas relações sociais (MERHY, 1997), não devendo ser reduzido à noção de posto de trabalho ou de emprego.

Em saúde, o trabalho sofre as consequências da reestruturação produtiva ocorrida no mundo a partir da década de 1970, com a crise do modelo taylorista-fordista, de execução de tarefas repetitivas e maçantes, mas bem pagas e que mantinham a política de Estado de Bem Estar Social (Welfare State). Estas mudanças foram sentidas no Brasil em meados dos anos 1990, caracterizada pela inovação tecnológica, pela descentralização da produção (aumento da terceirização e da formação de redes) e por mudanças nas formas de organização e gestão do trabalho.

O trabalho em saúde é parte do setor de serviços ou setor terciário da economia, mas tem características específicas e, como definiu Merhy (2007), dá-se através do "trabalho vivo em ato". Este processo ocorre sempre no encontro entre o profissional e o usuário do serviço de saúde. Ou seja, é um trabalho da esfera da produção não material, que se completa no ato de sua realização. Não tem como resultado um produto material, independente do processo de produção e comercializável. O produto é indissociável do processo que o produz; é a própria realização da atividade (PIRES, 2000 p.255).

O trabalhador da saúde desenvolve suas atividades de forma autônoma, numa relação profissional-cliente, ou em instituições públicas ou privadas como trabalho coletivo, que é a forma mais requerida nos dias atuais através da integração dos diversos saberes para o desenvolvimento de práticas de saúde.

Mesmo que autores como Barbara Starfield (2006) defendam que trabalho em equipe tenha sido criado para potencializar o trabalho dos médicos na Atenção Primária, devido à baixa oferta desses profissionais, a Estratégia de Saúde da Família (ESF) destaca o trabalho em equipe como diretriz, e preconiza que o processo de trabalho seja organizado:

[...] de forma multiprofissional, interdisciplinar, e em equipe, realizando a gestão do cuidado integral do usuário e coordenando-o no conjunto da rede de atenção. A presença de diferentes 
formações profissionais, assim como um alto grau de articulação entre os profissionais, é essencial, de forma que não só as ações sejam compartilhadas, mas também tenha lugar um processo interdisciplinar no qual progressivamente os núcleos de competências profissionais específicos vão enriquecendo o campo comum de competências, ampliando, assim, a capacidade de cuidado de toda a equipe (BRASIL, 2011, p. 22).

A equipe de Saúde da Família (eSF), composta basicamente de médico generalista ou de família, enfermeiro, técnico de enfermagem e agentes comunitários de saúde, tem como objetivo prestar atenção integral à saúde de uma população adstrita baseada no vínculo e na co-responsabilidade, com abordagem multidisciplinar, planejamento horizontal de ações, compartilhamento do processo decisório e estímulo à participação social, representando uma ruptura de práticas tradicionais, desconexas com as reais necessidades de saúde da população (BRASIL, 2011).

Porém, a concretização dessa diretriz esbarra na dificuldade de superar uma organização de trabalho compartimentalizada, em que cada profissional presta a sua assistência sem integração com os demais e, em alguns casos, até realizando esforços duplicados ou contraditórios. Além disso, o médico ainda permanece como o elemento central do processo assistencial em saúde. As demais profissões acabam atuando de forma subordinada às decisões médicas, com atividades delegadas pelos mesmos e mantendo certa autonomia, desde que não contrarie as decisões médicas (PIRES, 2000).

Um outro conceito importante de ser apreendido para essa discussão é o de emprego em saúde, que diz respeito às formas de inserção institucional dos profissionais no mercado de trabalho do setor. Sendo assim, o termo emprego refere-se a postos de trabalho e não a indivíduos (MÉDICI et al, 1992 apud MACIEL FILHO, 2007). Com origem na teoria econômica de John Keynes, os estudos sobre emprego dedicam-se aos impactos gerados pelas políticas públicas sobre a criação de postos de trabalho.

As políticas de saúde no Brasil têm sido tentativas de privilegiar a Atenção Primária e, nesse contexto, a estratégia de Saúde da Família vem sendo fortemente expandida nos últimos anos. De acordo com os dados disponíveis no site do Departamento de Atenção Básica do Ministério da Saúde, em 2014, já se faz presente em 5.403 dos 5.570 municípios brasileiros. O número de equipes aumentou 121,5\% em doze anos, passando de 16.734 eSF em 2002 para 37.064 em 2014, elevando a cobertura populacional da ESF em território nacional de 31,9\% pra 57,55\% no mesmo intervalo de tempo. Esta realide ainda está distante da garantia do direito universal à saúde. Porém, o avanço é evidente e esta expansão significativa da APS tem grande impacto na abertura de postos de trabalho e, consequentemente, elevou consideravelmente a demanda por profissionais médicos para ocupá-los.

A combinação de mudanças no mundo do trabalho e da profissão médica (perda da autonomia, assalariamento, condições de trabalho, incorporação tecnológica e especialização) com a expansão de cobertura da atenção básica aprofundou problemas preexistentes tais como as desigualdades 
na oferta de profissionais de ordens quantitativas (concentrações regionais) e qualitativas (proliferação de cursos em determinadas áreas de formação ou práticas pedagógicas que não consideram a integralidade), o aumento da precarização nos modos de contratação no Sistema Único de Saúde e baixa capacidade gestora tanto da formação quanto da prestação de serviços de saúde (PIERANTONI, 2004).

O cenário atual do mercado de trabalho em saúde, e que está inserido o mercado de trabalho médico, é consequência, do cenário político da década de 70, em que, segundo Médici (1986 apud MACIEL FILHO, 2007), as políticas de saúde e as políticas de formação e distribuição de Recursos Humanos estavam fortemente subordinadas aos mecanismos de custeio, pagamento e lucratividade, contribuindo para o problema da má distribuição de profissionais, especialmente médicos, entre as regiões brasileiras.

O mercado de trabalho médico é determinado basicamente por dois fatores institucionais: o sistema de ensino, que forma a oferta de profissionais, e o modelo de atenção à saúde, decisivo sobre a demanda e a composição da força de trabalho. E a regulação desta relação pode-se dar pela compra e venda da força de trabalho no mercado ou por intervenção estatal, em forma de política de saúde, que direcionará a produção e consumo de serviços de saúde segundo a lógica de mercado ou do bem estar social (MACIEL FILHO, 2007).

Os profissionais médicos são, segundo pesquisa da Fundação Getúlio Vargas (2008), os mais raros no mercado brasileiro e lideram todos os indicadores trabalhistas como taxa de ocupação (90\% estão empregados), média salarial (R \$6.270) e jornada de trabalho (50 horas semanais).

Nos últimos cinco anos, entre os anos de 2008 e 2013, a infraestrutura de saúde no Brasil cresceu em ritmo mais acelerado do que o número de médicos que atendem a população (Gráfico 1). No período, o total de equipamentos de saúde registrados pelo governo federal teve alta de $72,3 \%$. O número de leitos hospitalares subiu 17,3\% e o de estabelecimentos médicos, 44,5\% no Brasil. A oferta de médicos, porém, cresceu apenas 13,4\%.

Gráfico 1 - Incremento percentual no número de médicos, leitos hospitalares, estabelecimentos médicos e equipamentos de saúde. Brasil, 2008-2013.

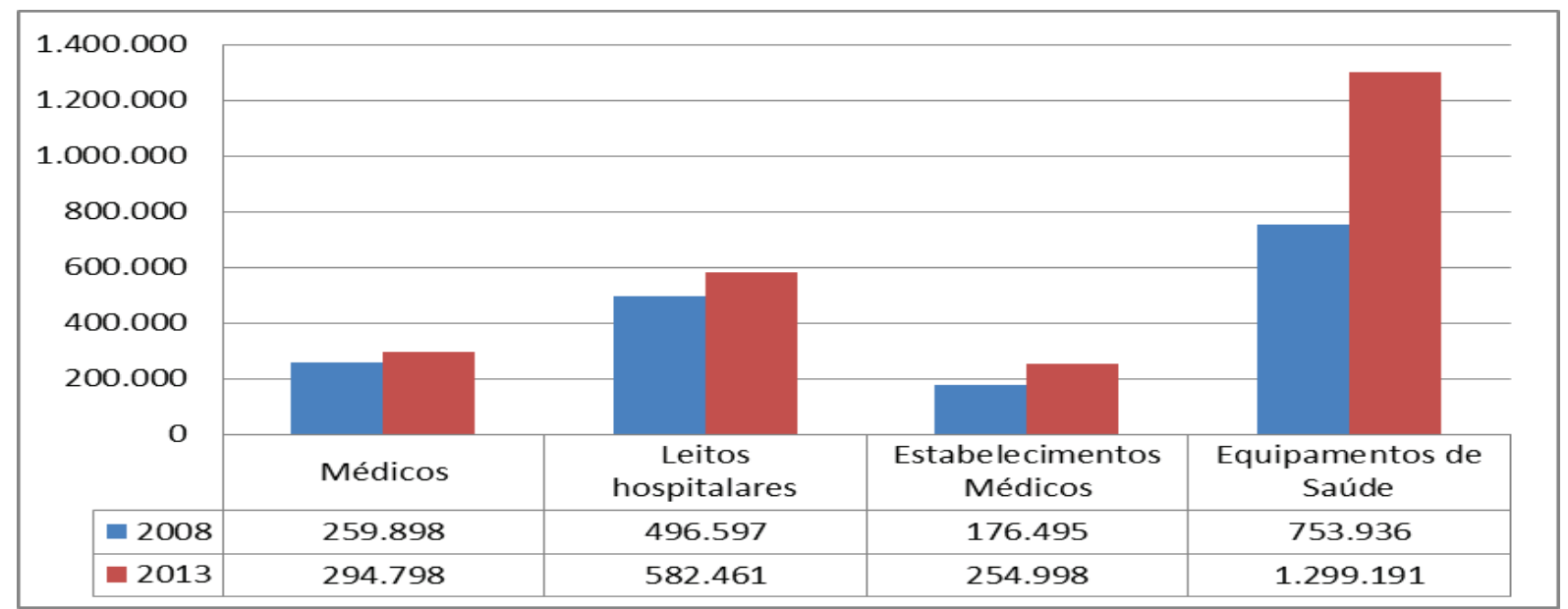

Fonte: Brasil, 2014. 
Considerando ainda que desses 294.798 médicos, o número correspondente aos que trabalham no SUS é de 215.640 (CONSELHO FEDERAL DE MEDICINA, 2013), podemos supor que a oferta de profissionais médicos no mercado de trabalho tem sido insuficiente diante da demanda decorrente do aumento significativo dos postos de trabalho, consequênciada expansão tanto da atenção básica assim como do mercado de planos e seguros se saúde.

De acordo com a Organização Mundial da Saúde (2012), o Brasil possui a razão de 1,8 médicos por mil habitantes. O que está aquém do necessário se comparado, por exemplo, a outros países detentores de sistema de saúde universal como o Reino Unido $(2,8)$ a Espanha $(3,9)$ e o Canadá $(2,0)$. O Brasil também fica atrás de países como os Estados Unidos $(2,4)$ e o Uruguai $(3,7)$ e da média das Américas(2,0).

A situação se agrava quando analisamos a distribuição regional desses médicos. As regiões sul e sudeste concentram $70 \%$ dos profissionais, mesmo represnetando $56 \%$ da população brasileira (Gráfico 2).

Gráfico 2 - Número de médicos por Região Brasil, 2013.

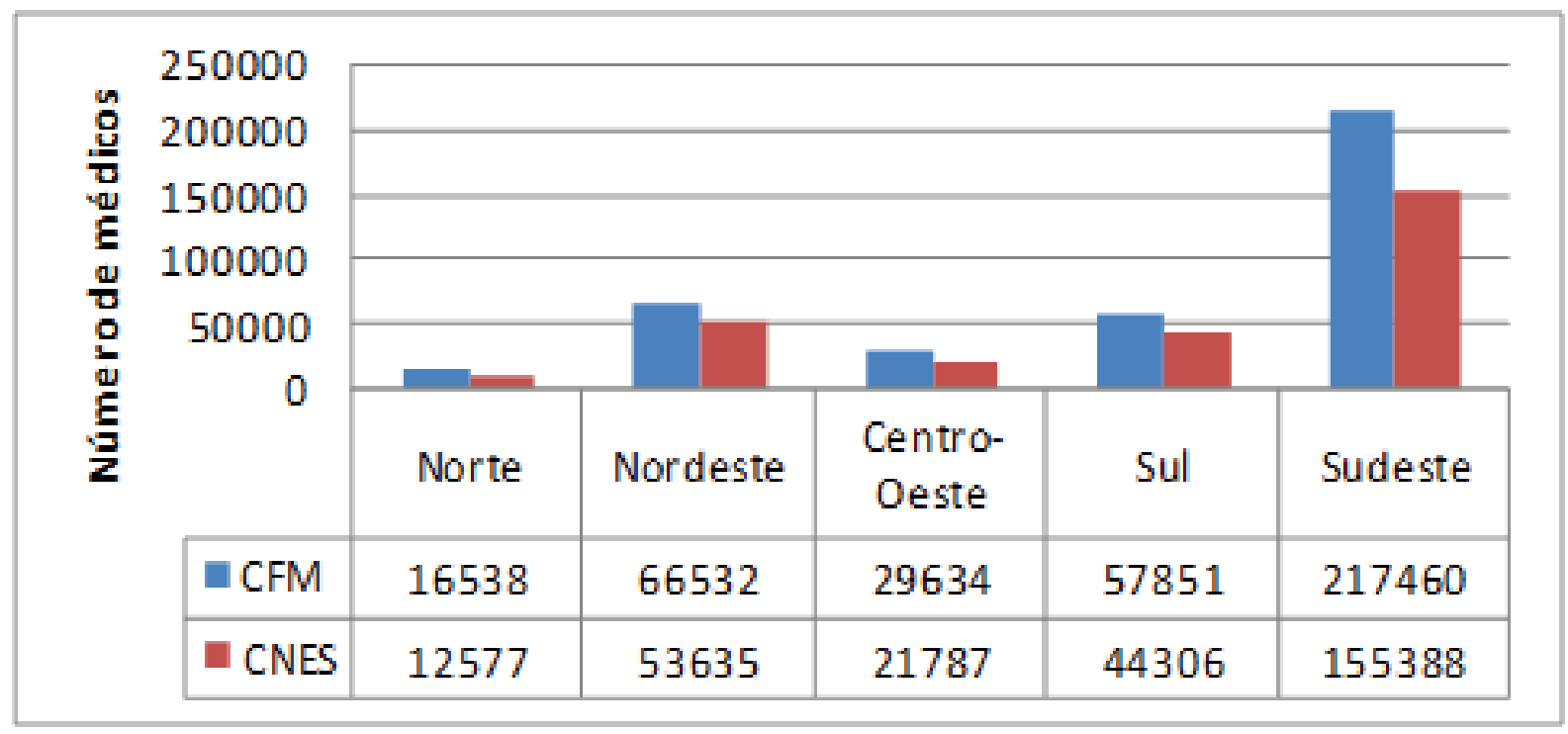

Fonte: Conselho Federal de Medicina (2013) e Brasil (2014) .

Entre os 27 estados (considerado Distrito Federal), 21 estão abaixo da média nacional de médicos por mil habitantes. $\mathrm{O}$ estado do Maranhão apresenta a pior realidade: 0,68 médicos por mil habitantes. Apenas os estados de São Paulo, Rio de Janeiro, Rio Grande do Sul, Espírito Santo, Minas Gerais e o Distrito Federal estão acima da média nacional (Figura 1). 
Figura 1 - Razão médicos por mil habitantes por estado. Brasil, 2013.

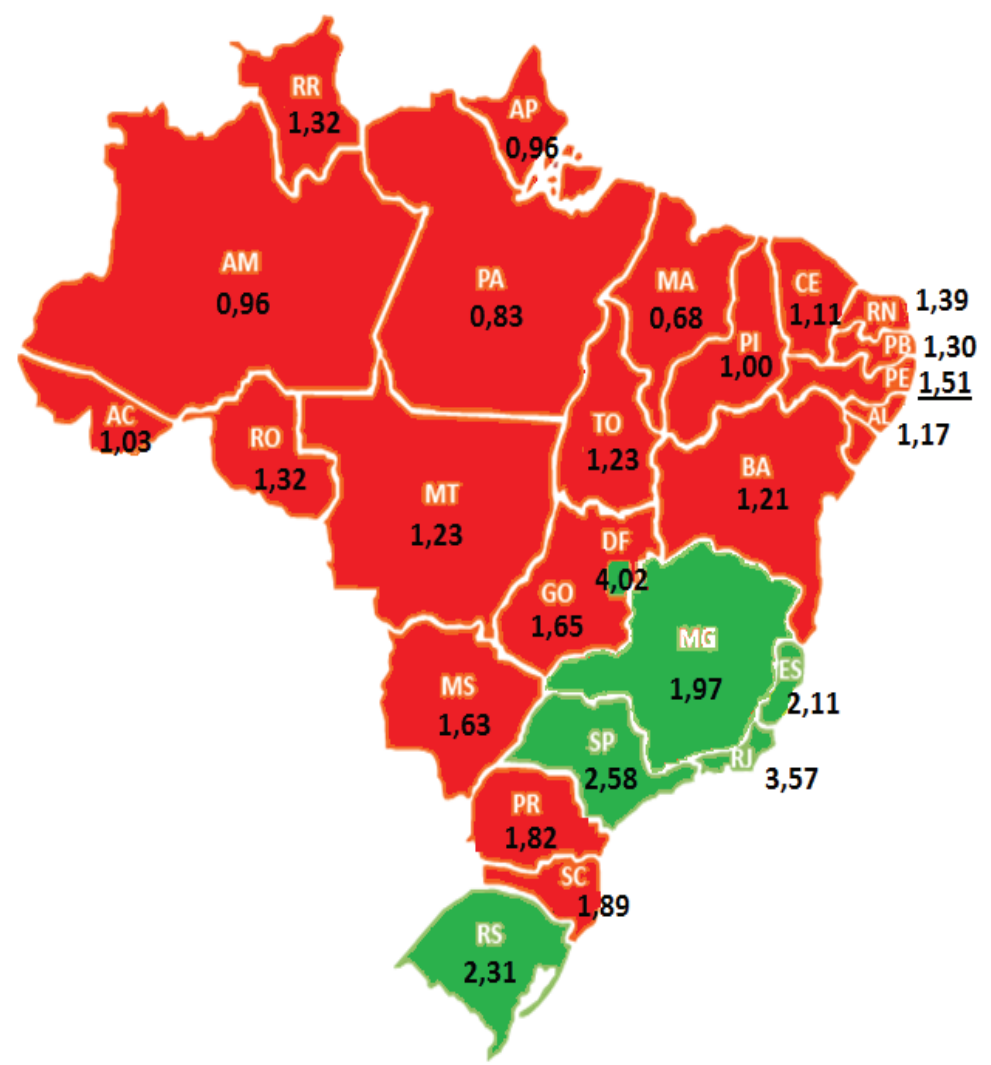

Fonte: Conselho Federal de Medicina (2013).

O Conselho Federal de Medicina (CFM), através da pesquisa Demografia Médica, publicada em 2013, demonstra essa diferença regional na distribuição dos médicos (Tabela 1).

Tabela 1 - Razão médicos por mil habitantes por estado. Brasil, 2013.

\begin{tabular}{lccc}
\hline UF/Brasil & Médico CFM* & População** & Razão*** \\
\hline Distrito Federal & 10.300 & 2.562 .963 & 4,02 \\
Rio de Janeiro & 57.175 & 15.993 .583 & 3,57 \\
São Paulo & 106.536 & 41.252 .160 & 2,58 \\
Rio Grande do Sul & 24.716 & 10.695 .532 & 2,31 \\
Espírito Santo & 7.410 & 3.512 .672 & 2,11 \\
Minas Gerais & 38.680 & 19.595 .309 & 1,97 \\
BRASIL & 371.788 & 190.732 .694 & 1,95 \\
Santa Catarina & 11.790 & 6.249 .682 & 1,89 \\
Paraná & 18.972 & 10.439 .601 & 1,82 \\
Goiás & 9.898 & 6.004 .045 & 1,65 \\
Mato Grosso do Sul & 3.983 & 2.449 .341 & 1,63 \\
Pernambuco & 13.241 & 8.796 .032 & 1,51 \\
Rio Grande do Norte & 4.392 & 3.168 .133 & 1,39 \\
Sergipe & 2.804 & 2.068 .031 & 1,36 \\
Roraima & 596 & 451.227 & 1,32
\end{tabular}




\begin{tabular}{lccc} 
Paraíba & 4.886 & 3.766 .834 & 1,30 \\
Tocantins & 1.771 & 1.383 .453 & 1,23 \\
Mato Grosso & 3.735 & 3.033 .991 & 1,23 \\
Bahia & 17.014 & 14.021 .432 & 1,21 \\
Alagoas & 3.659 & 3.120 .922 & 1,17 \\
Rondônia & 1.738 & 1.560 .501 & 1,11 \\
Ceará & 9.362 & 8.448 .055 & 1,11 \\
Amazonas & 3.828 & 3.480 .937 & 1,10 \\
Acre & 755 & 732.793 & 1,03 \\
Piauí & 3.125 & 3.119 .015 & 1,00 \\
Amapá & 643 & 668.689 & 0,96 \\
Pará & 6.300 & 7.588 .078 & 0,83 \\
Maranhão & 4.486 & 6.569 .683 & 0,68 \\
\hline
\end{tabular}

Fonte: Conselho Federal de Medicina (2013).

Nota: *Médicos registrados no Conselho Federal de Medicina.

**População geral (IBGE, 2010)

*** Razão médico registrado no CFM/Habitante geral (1.000 habitantes)

Essa desigualdade na distribuição de médicos também pode ser verificada em relação ao porte dos municípios. Os municípios de grande porte, com população acima de 500 mil habitantes concentram 48\% de todos os médicos do país (Gráfico 3), enquanto os menores municípios em termos de população ficam prejudicados em relação ao provimento desses profissionais.

Gráfico 3 - Distribuicão dos médicos por porte populacional dos municípios. Brasil. 2013.

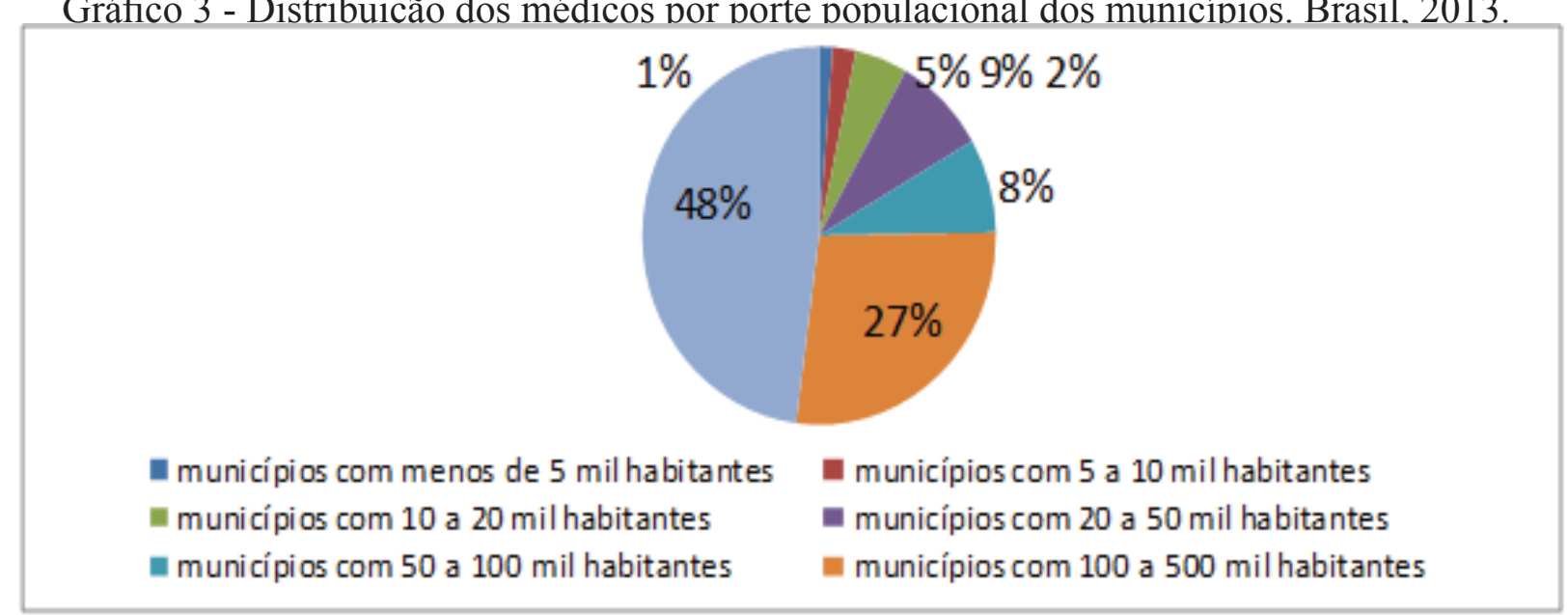

Fonte: Conselho Federal de Medicina (2013).

Há, ainda, segundo pesquisa publicada pelo Conselho Federal de Medicina (2012), um 
crescimento da concentração de médicos em favor da rede privada de saúde, que tem 4 vezes mais postos de trabalho médico ocupados que o setor público (SUS). Na região Nordeste, essa diferença é ainda maior: o setor publico tem taxa de ocupação dos postos de trabalho médico 6,7 vezes menor que o privado.

Além do aumento da demanda consequente à expansão da cobertura da Atenção Básica, estudos como os de Da Guarda (2009), Gugliemi (2006) e Maciel Filho (2007) abordam os desafios a serem superadaspara o provimento de médicos na Atenção Primária do SUS, que estão relacionados com a fixação desses profissionais, a rotatividade, a motivação e as condições de trabalho.

\section{ESCASSEZ DE MÉDICOS NA ATENÇÃO PRIMÁRIA EM PERNAMBUCO}

O Estado de Pernambuco possui atualmente a razão de 1,57 médicos por mil habitantes, abaixo da média nacional de 1,8. Dentro do estado, a desigualdade na distribuição de profissionais se reproduz: Recife, a capital do estado, tem razão de 6,27 médicos por mil habitantes, concentrando $69,32 \%$ de todos os médicos do estado.

De um total de 13.994 médicos em atividade em Pernambuco, 8.990 atuam no SUS. Em outras palavras, considerando apenas os médicos inseridos no SUS, a razão cai para 1,01 médicos por mil habitantes (Tabela 2).

Diante do exposto, podemos afirmar que o Estado de Pernambuco encontra-se abaixo da média nacional de médicos por mil habitantes, assim como no percentual desses profissionais que trabalham no SUS. Enquanto o Brasil tem 73\% dos seus médicos trabalhando no SUS, em Pernambuco, este número cai para 64\%. Ou seja, em Pernambuco, a quantidade de médicos disponíveis para o atendimento da parcela da população dependente exclusivamente do SUS é menor do que a média do Brasil e como agravante, encontra-se concentrada na capital do estado, Recife.

Tabela 2 - Razão médico por mil habitantes geral e no SUS. Pernambuco, 2013.

\begin{tabular}{lccc}
\hline & Médicos /CNES & População & Razão \\
\hline Brasil & 371.788 & 190.732 .694 & 1,95 \\
Pernambuco & 13.994 & 8.931 .028 & 1,57 \\
Recife & 9.702 & 1.546 .516 & 6,27 \\
Brasil /SUS & 215.640 & 190.732 .694 & 1,1 \\
Pernambuco/SUS & 8.990 & 8.931 .028 & 1,01 \\
Recife/SUS & 3.934 & 1.546 .516 & 2,54 \\
\hline
\end{tabular}

Fonte: Conselho Federal de Medicina (2013).

Diante do exposto, é primordial que o SUS assuma o papel definido na Constituição Federal de Tempus, actas de saúde colet, Brasília, 9(4), 11-34, dez, 2015. 


\section{$21 / /$}

1988 e, de fato, ordene a formação de médicos garantindo não só a distribuição, mas também que os médicos formados no Brasil tenham perfil voltado o trabalho no SUS e com o compromisso de constante busca pela melhoria dos níveis de saúde da população brasileira.

\section{PROGRAMA MAIS MÉDICOS}

O Programa Mais Médicos (PMM) foi criado através da Lei $N^{\circ} 12.871$, de 22 de Outubro de 2014, com a finalidade de ordenar a formação de recursos humanos na área médica, e surgiu como resposta à solicitação de prefeitos de municípios de todo o Brasil através de campanha da Frente Nacional dos Prefeitos entitulada "Cadê o médico?", iniciada em janeiro de 2013, com vistas a superar a carência de médicos principalmente nos municípios pequenos e de difícil acesso, como na periferia das grandes cidades.

O PMM é uma iniciativa intersetorial, coordenada pelos Ministérios da Saúde e da Educação em nível nacional, e em nível estadual envolve as Secretarias Estaduais e Municipais de Saúde e a instituições de ensino.

Os objetivos do PMM, segundo a lei que o criou são:

a) Diminuir a carência de médicos nas regiões prioritárias para o SUS, a fim de reduzir as desigualdades regionais na área da saúde;

b) Fortalecer a prestação de serviços de atenção básica em saúde no país;

c) Aprimorar a formação médica no país e proporcionar maior experiência no campo de prática médica durante o processo de formação;

d) Ampliar a inserção do médico em formação nas unidades de atendimento do SUS, desenvolvendo seu conhecimento sobre a realidade de saúde da população brasileira;

e) Fortalecer a política de educação permanente com a integração ensino-serviço por meio da atuação das instituições de educação superior na supervisão acadêmica das atividades desempenhada pelos médicos;

f) Promover a troca de conhecimentos e experiências entre profissionais da saúde brasileiros e médicos formados em instituições estrangeiras;

g) Estimular a realização de pesquisas aplicadas ao SUS.

Para consolidar esse objetivos, o PMM prevê ações nos seguintes eixos:

1) Reordenação da oferta de cursos de Medicina e de vagas para a residência médica, priorizando as regiões de saúde com menor relação de vagas e médicos por habitante e que 
tenha estrutura de serviços de saúde para ofertar campo de prática para os alunos.

2) Estabelecimento de novos parâmetros para a formação médica no país.

3) Promoção, nas regiões prioritárias do SUS, de aperfeiçoamento de médicos na área de atenção básica, mediante a integração ensino-serviço, inclusive por meio de intercâmbio internacional.

Os dois primeiros eixos tem estrita relação com a formação de médicos. Estabelecem critérios para a autorização para o funcionamento de cursos de Medicina, prioriza a formação na Atenção Básica e na urgência e emergência do SUS para o internato e os programas de residência médica, entre outras. São as ações mais estruturadoras do programa e que surtirão efeito em médio e longo prazos.

O terceiro eixo, que trata da chamada de médicos, é o Projeto Mais Médicos para o Brasil, foco deste trabalho.

\section{PROJETO MAIS MÉDICOS PARA O BRASIL}

Apesar de também tratar-se de uma ação de formação em serviço, o Projeto Mais Médicos para o Brasil (PMMB) tem o claro objetivo de prover profissionais médicos para as regiões consideradas prioritárias para o SUS por serem de difícil acesso, de difícil provimento de médicos ou que possuam populações em situação de maior vulnerabilidade.

Foram considerados prioritários os municípios quem se enquadravam em pelo menos um dos seguintes critérios:

1) Ter no município $20 \%$ ou mais da população vivendo em extrema pobreza, com base nos dados do Ministério do Desenvolvimento Social e Combate à Fome (MDS).

2) Estar entre os 100 municípios com mais de 80 mil habitantes, com os mais baixos níveis de receita "per capita" e alta vulnerabilidade social de seus habitantes;

3) Estar situado em área de atuação do Distrito Sanitário Especial Indígena (CSEI/ SESAI/MS), órgão integrante da Estrutura Regimental do Ministério da Saúde;

4) Estar nas áreas referentes aos $40 \%$ dos setores censitários com os maiores percentuais de população em extrema pobreza dos municípios (conforme alteração da Portaria MDS 1493/2013).

Para participar do Projeto, cada gestor municipal, voluntariamente, solicitou adesão e, após a demanda dos municípios prioritários serem atendidas, foi aberta a adesão para os municípios que não se enquadravam neste perfil, mas que também demonstraram necessidade de médicos. 
Após a adesão dos municípios, foi aberta a adesão para os médicos que desejassem participar do Projeto, com a seguinte ordem de prioridade:

1) Médicos formados no Brasil ou com diploma revalidado, ou seja, portadores de registro em Conselho Regional de Medicina Brasileiro. Este é, para o Projeto, o perfil profissional chamado "CRM Brasil". Nesta categoria, a grande maioria é composta por médicos brasileiros, mas há também estrangeiros com diploma revalidado.

2) Médicos brasileiros ou estrangeiros que se graduaram em medicina em Instituição de Ensino em paísescom a razão médicos/mil habitantes maior que a do Brasil. Estes médicos fazem parte do perfil "Intercambistas Individuais".

3) Médicos que aderiram ao Projeto através da Cooperação Internacional com a OPAS, para preencher as vagas remanescentes de solicitações pelos gestores municipais que não foram preenchidas pelas duas categorias listadas anteriormente, os "Intercambistas Cooperados".

Aos médicos participantes do Projeto Mais Médicos para o Brasil é ofertado um curso de especialização em Saúde da Família em instituição pública de educação superior vinculada à Universidade Aberta do SUS.

Os médicos participantes do Projeto desenvolvem suas atividades em carga horária semanal de 40 horas. Destas, 32 horas são de atividades de integração ensino-serviço em unidades básicas de saúde, inseridos em equipes de Saúde da Família, e 8 horas são dedicadas às atividades específicas do curso de especialização.

Outra oferta educacional para os médicos participantes do Projeto é a supervisão contínua coordenada pelas tutorias acadêmicas das universidades que realizaram adesão ao PMM.

A condição de participante após aprovação nos módulos de acolhimento e avaliação garantiu aos médicos intercambistas a autorização para o exercício da Medicina exclusivamente no âmbito do Projeto e o Ministério da Saúde emitiu números de registro único para cada médico intercambista e a respectiva carteira de identificação.

A fiscalização do exercício do trabalho dos médicos, mesmo os com registro do Ministério da Saúde, continuaram a cargo dos Conselhos Regionais de Medicina.

O Projeto Mais Médicos para o Brasil, de acordo com o último levantamento do Ministério da Saúde, em Agosto de 2014, tem 14.062 médicos em mais de 3.700 municípios em todo o território nacional, atendendo uma população estimada superior a 42 milhões de pessoas. 


\section{PROCEDIMENTOS METODOLÓGICOS}

\section{TIPO DE ESTUDO}

Trata-se de um estudo de desenho ecológico espacial, considerando como unidade de análise o Estado de Pernambuco e como medida de análise de cobertura da estratégia de saúde da família a razão de média do número de médicos antes e depois do período de implantação do PMMB entre outubro de 2013 e julho de 2014.

\section{LOCAL DE ESTUDO}

O estudo foi realizado no Estado de Pernambuco, Região Nordeste do Brasil, com extensão territorial de $98.311,616 \mathrm{~km}^{2}$, limitado ao Norte pelos estados da Paraíba e Ceará, ao Leste com o oceano Atlântico, ao Oeste e ao Sul com os estados do Piauí e Bahia e ao Sul com o estado de Alagoas. Estado está dividido em quatro macrorregiões (Região Metropolitana do Recife- RMR, Zona da Mata, Agreste e Sertão) e 12 Regiões de Saúde (Figura 2).

Figura 2 - Mapa das Regiões de Saúde. Pernambuco, 2013.

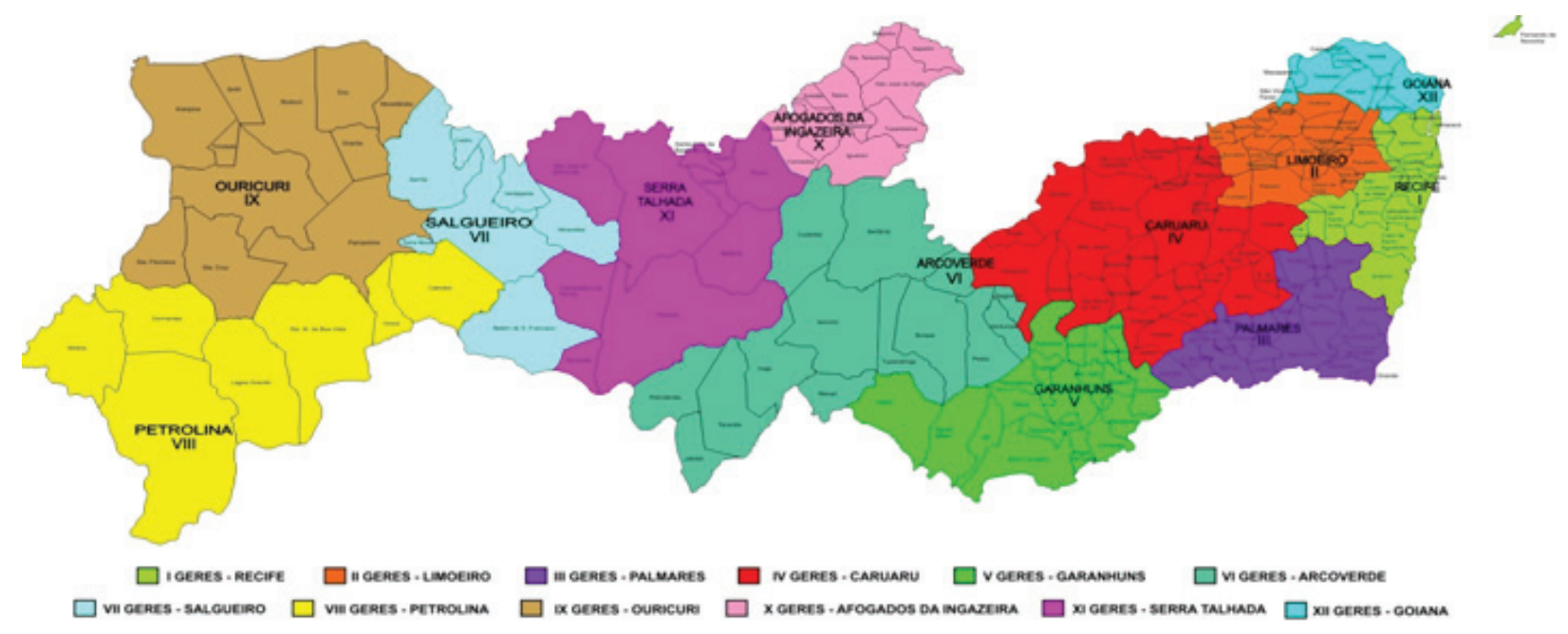

É o sétimo estado mais populoso do Brasil e o décimo mais rico, e a capital, Recife, ocupa o lugar de maior Produto Interno Bruto das capitais do Nordeste. Está dividido em 184 municípios e um território estadual (Fernando de Noronha).

Segundo dados do Censo 2010 (IBGE, 2010), a população pernambucana naquele ano foi de 8.796.448 habitantes, o que equivale a uma densidade demográfica de 89,63 habitantes $/ \mathrm{km}^{2}$.

O Índice de Desenvolvimento Humano (IDH) de Pernambuco é de 0,718. De acordo com os dados divulgados em 2010 pelo Programa das Nações Unidas para o Desenvolvimento (PNUD), o Estado ocupa a $23^{\circ}$ posição no ranking dos estados brasileiros e em relação à região Nordeste encontra-se na $5^{\circ}$ posição. 


\section{FONTE E COLETA DE DADOS}

No estudo foram utilizados dados do Projeto Mais Médicos para o Brasil do Ministério da Saúde e dos sistemas de informação do Departamento de Atenção Básica do referido ministério.

Foram consultados os documentos do Programa Mais Médicos, como editais de adesão de médicos e de municípios, portarias e a Lei Federal $N^{\circ} 12.871$. Em seguida o banco de dados em Excel disponibilizado pelo Ministério da Saúde contendo informações sobre perfis e lotação dos médicos do Projeto Mais Médicos para o Brasil.

As informações a respeito de população foram retiradas do endereço eletrônico do Instituto Brasileiro de Geografia e Estatística (IBGE). Sobre as equipes de Saúde da Família, do Cadastro Nacional de Estabelecimentos de Saúde (CNES) e do endereço eletrônico do Departamento de Atenção Básica (DAB), do Ministério da Saúde. Os números de médicos e distribuição dos mesmos foram obtidos nas publicações do Conselho Federal de Medicina.

\section{ASPECTOS ÉTICOS}

Por se tratar de estudo descritivo, não envolvendo diretamente seres humanos, respeitados os preceitos da Resolução 466/2012 do Conselho Nacional de Saúde, não foi necessária a aprovação desta pesquisa por Comitê de Ética em Pesquisa Envolvendo Seres Humanos.

\section{RESULTADOS}

OS MÉDICOS DO PROJETO MAIS MÉDICOS PARA O BRASIL NO ESTADO DE PERNAMBUCO

\section{Distribuição Espacial dos profissionais}

Os médicos do Projeto Mais Médicos para o Brasil foram lotados nos municípios pernambucanos em 5 ciclos, o primeiro iniciando no mês de outubro de 2013. A cada ciclo, abriu-se edital para os médicos interessados em realizar a inscrição no Projeto de acordo a seguinte ordem de prioridade:

1) Médicos formados no Brasil ou com diploma revalidado, ou seja, portadores de registro em Conselho Regional de Medicina Brasileiro. Este é, para o Projeto, o perfil profissional chamado "CRM Brasil". Nesta categoria, a grande maioria é composta por médicos brasileiros, mas há também estrangeiros com diploma revalidado.

2) Médicos brasileiros ou estrangeiros que se graduaram em medicina em Instituição de Ensino em paísescom a razão médicos/mil habitantes maior que a do Brasil. Estes médicos fazem parte do perfil "Intercambistas Individuais". 
3) Médicos que aderiram ao Projeto através da Cooperação Internacional com a OPAS, para preencher as vagas remanescentes de solicitações pelos gestores municipais que não foram preenchidas pelas duas categorias listadas anteriormente, os "Intercambistas Cooperados".

A cada ciclo, os médicos formados no Brasil, apresentaram-se diretamente nos municípios e iniciavam suas atividades, enquanto os Intercambistas (Individuais e Cooperados) passaram por um módulo de Acolhimento e Avaliação nacional com duração de três semanas e estadual, de uma semana, em que puderam aprofundar conhecimentos sobre o sistema de saúde brasileiro, o processo de trabalho em Saúde da Família e o perfil epidemiológico regional, assim como ter noções básicas de língua portuguesa. Somente após aprovação neste módulo, os médicos Intercambistas puderam ser inseridos na Atenção Primária nos municípios.

Houve algumas desistências e a migração de 21 médicos do Programa de Valorização do Profissional de Atenção Básica (PROVAB) para o PMMB.

De acordo com o último levantamento do Ministério da saúde, em Agosto de 2014, o Projeto Mais Médicos do Brasil atinge a escala de 663 médicos atuando no território do estado, em 143 dos 185 municípios pernambucanos, representando 77,2\% deles. A implantação destes profissionais de acordo com cada um dos ciclos está representada na Figura 3 e tem o quantitativo abaixo descrito:

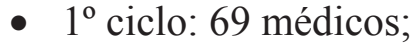

- $2^{\circ}$ ciclo: 352 médicos, em duas etapas;

- $3^{\circ}$ ciclo: 89 médicos;

- $4^{\circ}$ ciclo: 43 médicos;

- $5^{\circ}$ ciclo: 76 médicos; 
Figura 3 - Municípios com médicos do Projeto Mais Médicos para o Brasil ao fim de cada ciclo. Pernambuco, 2013-2014.
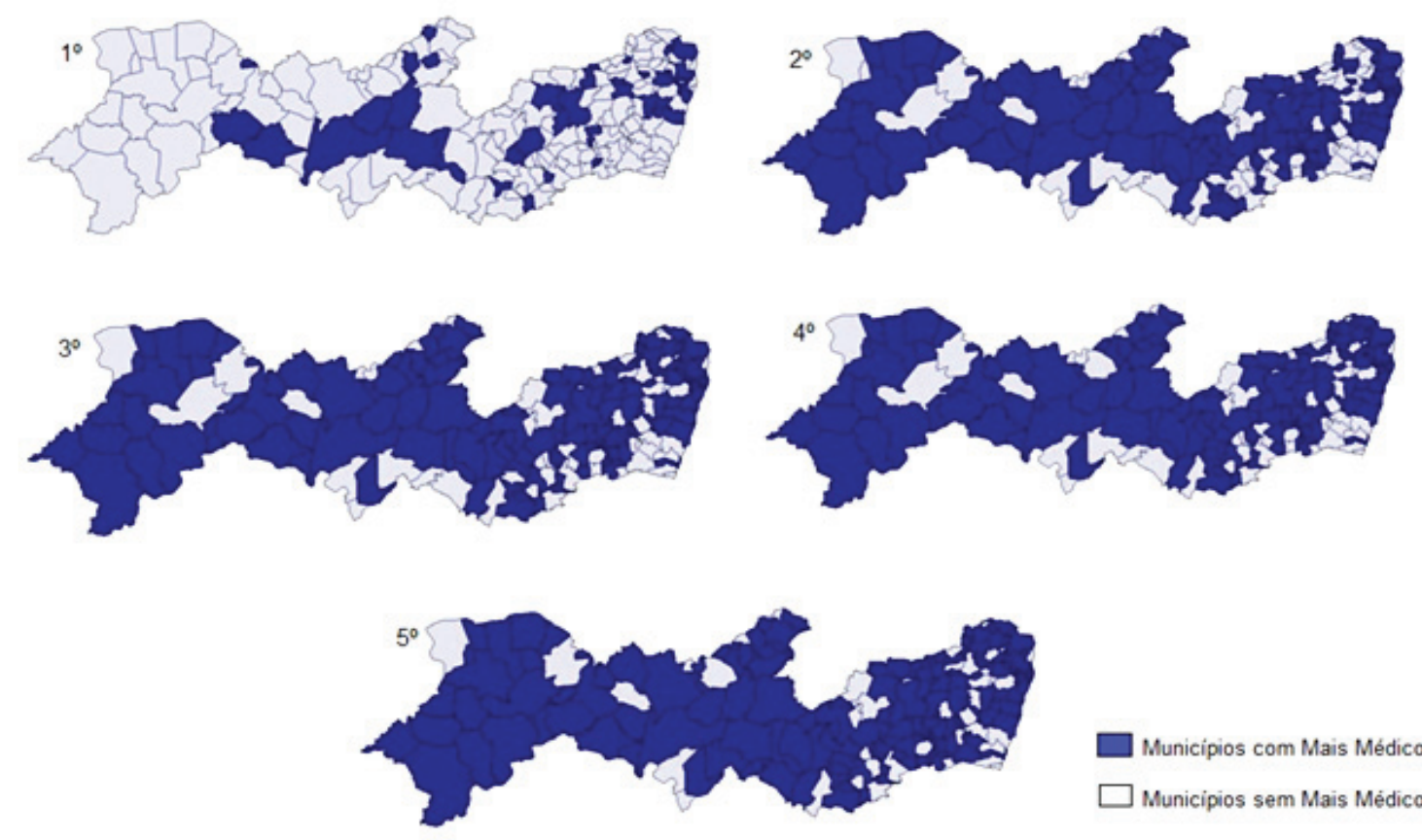

Municipios com Mais Médicos

Municipios sem Mais Médicos

Fonte: Brasil (2014).

Destes 663 médicos, 13 foram lotados no Distrito Sanitário Indígena do estado, sendo assim, apesar de estarem numericamente representados nos municípios em que estão atuando, não se encontram em equipe de Saúde da Família convencional.

O mapa final da distribuição dos profissionais do PMMB em Pernambuco praticamente coincide com a distrubição das equipes de Saúde da Família do estado, presente na quase totalidade dos municípios, incluindo aqueles mais longínquos e de mais difícil acesso e permanência, como os municípios do sertão.

Em relação à distribuição de médicos por Região de Saúde do estado, se lançássemos o olhar apenas sobre os números de profissionais, ficaríamos com a impressão que o Projeto simplesmente reproduziu a concentração na região metropolitana do estado, localizada na I Região de Saúde, com sede em Recife. Mas ao comparar esses números com o percentual da população pernambucana que vive nessas regiões, veremos que essa distribuição é equânime e busca superar as desigualdades regionais de distribuição dos médicos (Tabela 3). 
Tabela 3 - Distribuição dos médicos do Projeto Mais Médicos para o Brasil por Região de Saúde. Pernambuco, 2014.

\begin{tabular}{|c|c|c|c|c|}
\hline $\begin{array}{l}\text { Região de } \\
\text { Saúde }\end{array}$ & Sede & \% População & $\mathrm{N}^{0}$ médicos $\mathrm{PMMB}$ & \% Médicos PMMB \\
\hline I & Recife & 44,4 & 151 & 22,5 \\
\hline II & Limoeiro & 6,4 & 42 & 6,2 \\
\hline III & Palmares & 6,5 & 58 & 8,6 \\
\hline IV & Caruaru & 14,1 & 131 & 19,5 \\
\hline $\mathbf{V}$ & Garanhuns & 5,8 & 46 & 6,8 \\
\hline VI & Arcoverde & 4,3 & 50 & 7,4 \\
\hline VII & Salgueiro & 1,6 & 14 & 2,0 \\
\hline VIII & Petrolina & 4,9 & 25 & 3,7 \\
\hline IX & Oricuri & 3,7 & 40 & 5.9 \\
\hline $\mathbf{X}$ & $\begin{array}{c}\text { Afogados da } \\
\text { Ingazeira }\end{array}$ & 2,1 & 33 & 4,9 \\
\hline XI & Serra Talhada & 2,5 & 37 & 5,5 \\
\hline XII & Goiana & 3,4 & 36 & 36 \\
\hline TOTAL & & 100 & 669 & 100 \\
\hline
\end{tabular}

Fonte: Brasil (2014).

\section{Perfil dos médicos}

Para este estudo, os perfis considerados foram: os de médicos participantes do PMMB previstos nos editais, a saber: CRM Brasil, Intercambistas Individuais e Intercambistas Cooperados; a nacionalidade e o país de graduação em medicina de cada médico.

Considerando estes três perfis de participantes do Projeto em Pernambuco, pudemos observar que, no momento de implantação, houve um grande predomínio dos intercambistas cooperados (76\%), seguido dos CRM Brasil (18\%) e por fim dos intercambistas individuais (6\%), distribuição muito próxima da nacional: CRM Brasil: 11\%, Intercambistas Individuais: $8 \%$ e Intercambistas Cooperados: 81\% (Gráfico 4).

Por outro lado observando ainda as informações do MS sobre a nacionalidade dos médicos Intercambistas Individuais, percebe-se que 21 têm nacionalidade brasileira, o que sugere que o Projeto representou uma oportunidade para profissionais brasileiros que concluíram a graduação em medicina no exterior possam voltar para o seu país e exercer a profissão. 
Gráfico 4 - Proporção dos médicos do Projeto Mais Médicos para o Brasil segundo perfil. Pernambuco e Brasil, 2014.

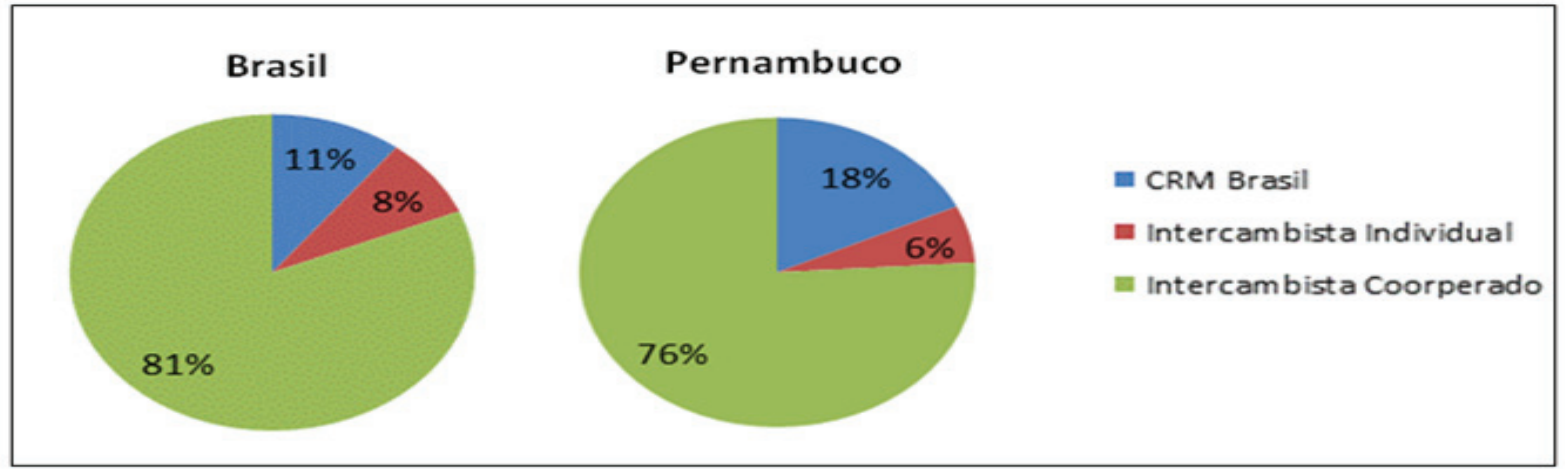

Fonte: Brasil (2014).

De acordo com a nacionalidade dos médicos, os cubanos são predominantes $(77,5 \%)$, seguidos pelos brasileiros (20,6\%) e, em menor número, de outros países da Europa (Espanha e Itália) e da América Latina (Argentina, Venezuela, Uruguai, Colômbia e Paraguai) (Tabela 5).

Os números relacionados ao país de formação dos médicos praticamente é igual a proporção em relação à nacionalidade dos mesmos. A maior parte das diferenças é decorrente dos brasileiros que se graduaram no exterior. Podemos observar também o aumento no número de profissionais formados na Espanha, na Venezuela e em Cuba, desde que apresentam maior número de graduados em relação a nacionalidade. Estes países possuem escolas com tradição em formação qualificada de profissionais para a Atenção Primária á Saúde, desconstruindo o argumento de que os brasileiros participantes do projeto viriam das escolas médicas da Bolívia ou de outros países da América Latina com menos tradição em Atenção Primária ou consideradas de menor qualidade (Tabela 4).

Tabela 4 - Frequência de médicos do Projeto Mais Médicos para o Brasil segundo nacionalidade e país de graduação. Pernambuco, 2014.

\begin{tabular}{cccc}
\hline Nacionalidade & Número de médicos & País de graduação & Número de médicos \\
\hline Cuba & 514 & Cuba & 522 \\
Brasil & 137 & Brasil & 122 \\
Espanha & 4 & Espanha & 8 \\
Argentina & 3 & Venezuela & 7 \\
Venezuela & 3 & Argentina & 2 \\
Uruguai & 2 & Uruguai & 2 \\
Colômbia & 1 & Alemanha & 1 \\
Itália & 1 & Itália & 1 \\
Paraguai & 1 & Portugal & 1 \\
\hline
\end{tabular}

Fonte: Brasil (2014). 


\section{A DISTRIBUIÇÃO DOS MÉDICOS E OS PERFIS DOS MUNICÍPIOS}

Tomando como base a Portaria N $\mathrm{N}^{\mathrm{0}} 1.377$, de 13 de Junho de 2011, foram utilizados os critérios de definição das áreas e regiões prioritárias, segundo carência e dificuldade de retenção de médico, como perfis dos municípios participantes do Projeto Mais Médicos para o Brasil, agrupados por ordem de prioridade:

a) "POBREZA" - municípios com 20\% (vinte por cento) ou mais da população vivendo em alta vulnerabilidade social, com base nos dados do Ministério do Desenvolvimento Social e Combate à Fome;

b) "G100" - Os cem Municípios com mais de 80 mil habitantes, com os mais baixos níveis de receita pública "per capita” e alta vulnerabilidade social de seus habitantes;

c) "DSEI" - município situado em área de atuação de Distrito Sanitário Especial Indígena (DSEI/SESAI/MS), órgão integrante da Estrutura Regimental do Ministério da Saúde;

d) Capital ou região metropolitana em que existam áreas com populações em situação de maior vulnerabilidade.

A participação dos municípios no PMMB atendeu aos critérios de maior necessidade de provimento de médicos. Dos 143 municípios participantes, 103 (72\%) estão enquadrados na situação de "POBREZA" e nesta categoria, foram alocados 58\% dos médicos do Projeto, seguido de $11(7,6 \%)$ dos municípios, classificados como G100 e que concentrou 20\% dos médicos. (Tabela 5).

Esta situação reforça a importância do Projeto, pelo caráter de provimento emergencial nas áreas de maior carência do profissional, enquanto os demais eixos do Programa Mais Médicos se estabelecem a médio e longo prazos.

Tabela 5 - Distribuição dos médicos segundo perfis dos municípios participantes do Projeto Mais Médicos para o Brasil. Pernambuco, 2014.

\begin{tabular}{cccc}
\hline Perfil do município & $\mathbf{N}^{\mathbf{0}}$ e (\%) de municípios & $\begin{array}{c}\mathbf{N}^{\mathbf{0}} \text { médicos } \\
\text { PMMB }\end{array}$ & $\begin{array}{c}\text { \% médicos } \\
\text { PMMB }\end{array}$ \\
\hline POBREZA & $103(72)$ & 388 & 58 \\
G100 & $11(7,6)$ & 135 & 20 \\
CAPITAL E R. & $4(2,7)$ & 55 & 8,2 \\
METROPOLITANA & - & 13 & 2 \\
DSEI & $25(17,4)$ & 78 & 11,6 \\
OUTROS & $143(100)$ & 669 & 100 \\
TOTAL & &
\end{tabular}

Fonte: Brasil (2014). 


\section{INCREMENTO NO NÚMERO DE MÉDICOS NO ESTADO E CAPITAL}

Apesar da capital do estado, Recife, ter recebido o número de 37 médicos (5,5\% dos médicos do Projeto), com pequeno crescimento da razão de médicos por mil habitantes (antes 6,27 e depois $6,30)$, dados bem acima do preconizado pela OMS (2,7/mil), os critérios de prioridade do projeto contribuiu para crescimento maior desta razão no interior do estado em 4,74\%. Revela, portanto uma contribuição, ainda que discreta, do Projeto para a diminuição relativa da concentração de médicos na capital do estado. Considerando apenas os médicos do SUS fica ainda mais evidente a ampliação da equidade na distribuição dos médicos quando comparado a capital com o estado (Tabela 6).

Tabela 6 - Incremento da razão médicos por mil habitantes após implantação do Projeto Mais Médicos para o Brasil. Pernambuco, 2014.

\begin{tabular}{lccccc}
\hline & $\begin{array}{c}\text { Médicos } \\
\text { CNES* }\end{array}$ & $\begin{array}{c}\text { Razão } \\
\text { Antes } \\
\text { PMMB }\end{array}$ & $\begin{array}{c}\text { No Médicos }_{\text {Mais }}^{\text {Médicos*** }} \\
\text { Razão Pós } \\
\text { PMMB }\end{array}$ & $\begin{array}{c}\text { Incremento } \\
\text { (\%) }\end{array}$ \\
\hline Pernambuco & 13.994 & 1,57 & 663 & 1,64 & 4,74 \\
Recife & 9.702 & 6,27 & 37 & 6,30 & 0,30 \\
Pernambuco/SUS & 8.990 & 1,01 & 663 & 1,08 & 7,37 \\
Recife/SUS & 3.934 & 2,54 & 37 & 2,57 & 0,94 \\
\hline
\end{tabular}

Fonte: Conselho Federal de Medicina (2013), IBGE (2010) e Brasil (2014).

\section{VARIAÇÃO DA COBERTURA DA ESTRATÉGIA DE SAÚDE DA FAMÍLIA}

Em junho de 2014 o estado computava 2.095 equipes de Saúde da Família (eSF). Destas, 663 estão constituídas com médicos do Projeto Mais Médicos para o Brasil, o que corresponde a 31\% das equipes. Considerando o parâmetro da Política Nacional de Atenção Básica (BRASIL, 2011), de 3.000 pessoas por equipe de Saúde da Família, o PMMB oportunizou o acesso ao atendimento médico na APS de uma população estimada de 1.989 .000 pessoas no estado.

Comparando o período de 2011/2013, anterior à sanção da Lei do Programa Mais Médicos, com 2014 após aprovação da Lei e impolementação do Projeto, observa-se que houve incremento de cobertura de 5\% da Estratégia de Saúde da Família por contribuição PMMB (Tabela 7).

Permite-se dizer, ainda, que se trata de aumento de cobertura qualificada, à medida que esses profissionais estão inseridos em regime de 40 horas semanais, formação adequada ao trabalho na atenção primária, cursando especialização em Saúde da Família e supervisionados por universidades do estado. Supervisão realizada por médicos, preceptores de residências e professores, na sua maioria com formação em medicina de família e comunidade. 
Tabela 7 - Número e proporção de cobertura estimada da Estratégia de Saúde da Família, antes (junho dos anos 2011, 2012, 2013) e depois do PMMB (junho/ 2014). Pernambuco, 2014.

\begin{tabular}{ccccc}
\hline Ano / mês & 2011/junho & 2012/junho & 2013/junho & 2014/junho \\
\hline ESF implantadas & 1.876 & 1.867 & 1.964 & 2.095 \\
População coberta* & 6.008 .320 & 6.005 .471 & 6.281 .693 & 6.645 .412 \\
Cobertura (\%)** & 68,3 & 67,74 & 70,86 & 74.41 \\
\hline
\end{tabular}

Fonte: Ministério da Saúde, Brasil (2014) e IBGE (2010).

Nota:* Estimativa da população coberta

** Proporção de cobertura populacional estimada

\section{CONSIDERAÇÕES FINAIS}

A expansão da cobertura e o fortalecimento da Atenção Primária à Saúde juntamente com a ordenação da formação dos médicos são horizontes imprescindíveis para a consolidação do SUS no país e devem ser tratados como prioridades.

O estudo pode demonstrar que mesmo não sendo o Programa Mais Médicos voltado exclusivamente para o provimento de profissionais médicos, um de seus eixos, o Projeto Mais Médicos para o Brasil vem provendo um número significativo de médicos na Atenção Primária dos municípios do estado, considerando as áreas de maior necessidade, como preconiza o projeto. Apontou a dimensão espacial deste provimento assim como o incremento na cobertura da estratégia de saúde da família, significando um passo importante na garantia da diminuição das distorções na distribuição de médicos no território e a oportunidade de expansão da atenção à saúde a populações antes descobertas. Além de apontar para a qualificação da APS, pelo perfil, sistema de formação e processo de supervisão dos médicos alocados nos municípios, condições estabelecidas no projeto. Desta maneira fortalece a APS no estado o que deve ser refletido na melhoria dos indicadores de saúde da população coberta.

Com a realização deste estudo ficou evidente a necessidade de outros estudos capazes de analisar de forma mais aprofundada o aumento na cobertura da Estratégia de Saúde da Família em Pernambuco, assim como o projeto tem efetivamente contribuído para a garantia da qualidade de saúde e vida da população.

Por outro lado é importante registrar que, pela primeira vez no Brasil, o SUS assume, de fato, o seu papel estabelecido na Constituição Federal de 1988, quando em 2013 concebe e implanta um programa que, concretamente, vem ordenador a formação de trabalhadores para a saúde, o Programa Mais Médicos.

\section{REFERÊNCIAS BIBLIOGRÁFICAS}

BAPTISTA, T. W. de F.; FAUSTO, M. C. R.; CUNHA, M. S. Análise da produção bibliográfica sobre atenção primária à saúde no Brasil em quatro periódicos selecionados. 
Physis, Rio de Janeiro, v.19, n.4, 2009. Disponível em: <http:/www.scielo.br/pdf/physis/v19n4/ v19n4a06.pdf>. Acesso em: 28 jun. de2014.

BRASIL, Ministério da Saúde. Lei Federal No 12.871, de 22 de Outubro de 2013. Diário Oficial [da] República Federativa do Brasil, Poder Executivo, Brasília, DF, v. , n. , p. , 23 out 2013. Disponível em: <http://www.planalto.gov.br/ccivil_03/_ato2011-2014/2013/Lei/L12871. htm>. Acesso em: 10 jul 2014.

Portaria $\mathrm{N}^{\mathrm{o}} 2.488$, de 21 de Outubro de 2011. Diário Oficial [da]

República Federativa do Brasil, Poder Executivo, Brasília, DF, 2011. Disponível em: $<$ http://189.28.128.100/dab/docs/publicacoes/geral/pnab.pdf $>$ Acesso em: 2 jul 2014.

. Profissionais Ativos. Brasília, 2013. Planilha de Excel.

Programa Mais Médicos. Brasília, 2014. Apresentação de Power Point.

CARVALHO, M. S.; SOUSA, M. F. de. Como o Brasil tem enfrentado o tema provimento de médicos?. Interface, Botucatu, v.17, n.47, p. 913-926, 2013. Disponível em: < http://www.scielo. br/pdf/icse/v17n47/12.pdf>. Acesso em: 10 jun. 2014.

CONILL, E. M. Ensaio histórico-conceitual sobre a Atenção Primária à Saúde: desafios para a organização de serviços básicos e da Estratégia Saúde da Família em centros urbanos no Brasil. Cadernos de Saúde Pública, Rio de Janeiro, v. 24, supl.1, p. S7-S27, 2008.

FORTUNA, C. M. et al . O trabalho de equipe no programa de saúde da família: reflexões a partir de conceitos do processo grupal e de grupos operativos. Revista Latino-Americana de Enfermagem, Ribeirão Preto, v. 13, n. 2, 2005. Disponível em: <http://www.scielo.br/scielo. php?script $=$ sci_arttext\&pid $=$ S0104-11692005000200020\&lng $=$ en\&nrm=iso $>$. Acesso em: 04 set. 2014.

GUARDA, F. R. B. Perfil sócio-demográfico e motivação dos médicos que compõem equipes de Saúde da Família na Região Metropolitana do Recife. 2009. Dissertação (Mestrado em Saúde Pública) - Centro de Pesquisas Aggeu Magalhães, Fundação Oswaldo Cruz, Recife, 2009.

MACIEL FILHO, R. Estratérias para a distribuição e fixação de médicos em sistemas nacionais de saúde: o caso brasileiro. 2007. Tese (Doutorado em Saúde Pública) - Centro de Pesquisas Aggeu Magalhães, Fundação Oswaldo Cruz, Recife, 2007.

MATTOS, R. A. de. A integralidade na prática (ou sobre a prática da integralidade). Cadernos de Saúde Pública, Rio de Janeiro, v. 20, n. 5, Oct. 2004. Disponível em: <http://www.scielo.br/ scielo.php?script $=$ sci_arttext\&pid $=$ S0102-311X2004000500037\&lng=en\&nrm=iso $>$. Acesso em: 04 set. 2014.

MENDES, E. V. Atenção Primária à Saúdeno SUS. Fortaleza: Escola de Saúde Públicado Ceará, 2002. 
. As redes de atenção à saúde. Ciência e Saúde Coletiva, Rio de Janeiro, v. 15, n.

5, 2010. Disponível em: <http://www.scielo.br/scielo.php?script=sci_arttext\&pid=S1413812320 10000500005\&lng=en\&nrm=iso $>$. Acesso em: 10 set. 2014.

MERHY, E.E.; A cartografia do trabalho vivo. São Paulo: Hucitec, 2007.

NERI, M. C; Escassez de médicos. Rio de Janeiro: Fundação Getúlio Vargas, 2008. Disponível em: < http://www.cps.fgv.br/ibrecps/medicos/index.htm>. Acesso em: 21 ago. 2014.

PERNAMBUCO. Secretaria Estadual de Saúde. Mapa das Regiões de Saúde. Recife, 2014. Disponível em: < http://portal.saude.pe.gov.br/secretaria-executiva-de-coordenacao-geral/ gerencias-regionais-de-saude>. Acesso em: 20 ago. 2014.

PIERANTONI, C. R.; VARELLA, T. C.; FRANÇA, T. Recursos humanos e gestão do trabalho em saúde: da teoria para a prática. In: BRASIL. Ministério da Saúde. Observatório de Recursos Humanos em Saúde no Brasil: estudos e análises. Brasília, 2004. v. 2.

PIRES, D. Novas formas de organização do trabalho em saúde e enfermagem. Revista Baiana de Enfermagem, Salvador, 2000; v. 13n.1/2 p.83-92, 2000.

PIRES, D. Reestruturação produtiva e conseqüências para o trabalho em saúde. Revista Brasileira de Enfermagem, Brasília, 2000; v. 53, p. 251-63. Disponível em: < http://www. scielo.br/pdf/reben/v53n2/v53n2a10.pdf>. Acesso em: 10 jul. 2014.

RIBEIRO, E. M.; PIRES, D.; BLANK, V. L. G. A teorização sobre processo de trabalho em saúde como instrumental para análise do trabalho no Programa Saúde da Família. Cadernos de Saúde Pública, Rio de Janeiro, v. 20, n. 2, abr. 2004. Disponível em: <http://www.scielosp.org/ scielo.php?script $=$ sci_arttext\&pid=S0102311X2004000200011\&lng=en\&nrm=iso $>$. Acesso em: 03 set. 2014.

SCHEFFER, M.; BIANCARELli, A.; CASSENOTE, A. Pesquisa Demografia Médica no Brasil: dados gerais e descrições de desigualdades. São Paulo: Conselho Regional de Medicina de São Paulo, 2013.

STARFIELD, B. Atenção primária. Equilíbrio entre necessidades de saúde, serviços e tecnologia. Brasília:Organização das Nações Unidas para a Educação,a Ciência e a Cultura e Ministério da Saúde, 2004. 